\title{
Internal medicine network: a new way of thinking hospital-territory integration and public-private partmership
}

\author{
Filomena Pietrantonio, ${ }^{1}$ Emilio Scotti ${ }^{2}$ \\ ${ }^{1}$ Internal Medicine Unit, Manerbio Hospital, ASST-Garda, Manerbio (BS); ${ }^{2}$ Acute Internal Medicine Unit, INI Research Institute \\ and Clinic, Grottaferrata (RM), Italy
}

\begin{abstract}
This working proposal aims to establish an Internal Medicine Network (IMN) model for the appropriate management of the poly-pathological complex patient in the different phases of his illness natural hystory. The IMN is based on an organization recalling the Hub and Spoke system already used for existing specialized networks. The Internal Medicine Unit (IMU) is the natural destination of acutely ill patients suffering from systemic or multi-organ diseases. Three are the IMU specific tasks: i) to stabilize acute, severe, poly-pathologic and complex patients; ii) to develop difficult etiological diagnosis in these patients and in those who should necessarily be admitted to the hospital, not being possible, for different reasons, alternative routes; iii) to select the acute poly-pathological complex patient's priorities. The expected results of a new model of integration system inside the IMN are: i) reduction and rationalization of expenditure in the medical area, increasing effectiveness, quality and safety guaranteeing patient centrality; ii) patients stratification based on characteristics of gravity, acute illness, estimated duration of hospitalization; iii) reduction of inappropriate hospital admissions ensuring connections between hospital and primary care units; iv) definition of different care pathways for patients hospitalized due to non-communicable diseases; v) implementation of new common medical records. The public-private partnership inside the IMN could be able to increase appropriateness reducing health costs. Patient-centered problems assessment, together with integration, cooperation, coordination and effective communication are some simple rules useful to achieve tangible results in a complex system and the IMN model represents its practical application.
\end{abstract}

\section{Background}

This working proposal aims to establish an Internal Medicine Network (IMN) model that deals properly with poly-pathological complex patient management in the different phases of the natural history of his ill-

Correspondence: Filomena Pietrantonio, Internal Medicine Unit, Manerbio Hospital, ASST-Garda, via Lungomella Valsecchi 2, 25025 Manerbio (BS), Italy.

Tel.: +39.030.9929515 - Fax: +39.030.9929514.

E-mail: filomena.pietrantonio@gmail.com

Key words: Internal Medicine Network; poly-pathological patients; integrated care; Internal Medicine core competencies; clinical data sharing.

Conflict of interest: the authors declare no potential conflict of interest.

Received for publication: 16 July 2016.

Revision received: 27 September 2016.

Accepted for publication: 27 September 2016.

This work is licensed under a Creative Commons Attribution NonCommercial 4.0 License (CC BY-NC 4.0).

(C) Copyright F. Pietrantonio and E. Scotti, 2017

Licensee PAGEPress, Italy

Italian Journal of Medicine 2017; 11:85-94

doi:10.4081/itjm.2016.764 ness. The IMN is based on an organization according to the Hub and Spoke system already used for existing specialized networks.

\section{The framework}

According to the World Health Organization (WHO), the four major non-communicable diseases (NCDs) (cardiovascular diseases, cancer, chronic obstructive pulmonary disease and diabetes) account for nearly $86 \%$ of all deaths and $77 \%$ of the European disease burden. In Europe for every $10 \%$ increase in NCD mortality, economic growth is reduced by $0.5 \% .{ }^{1,2}$

In Italy, as in other Developed Countries, a large share of economic resources is absorbed by chronic conditions management. A percentage of $65-70 \%$ of health care spending is used to treat NCDs in the different illness phases. ${ }^{3}$

WHO supports processes aligned to a people-centered philosophy. Accounting for people's holistic needs is an important step in planning and designing of the delivery of health services. ${ }^{4}$

The number of frail patients for whom the care of a single pathological episode necessarily requires both a global approach and a close connection with the local health services and social services is progressively growing. Chronic care model (CCM) addresses these changed needs highlighting patient centricity and enhancing community social and health support, 
in order to keep chronic, frail, poly-pathological people at home or out of the hospital, providing a social and health care continuum. ${ }^{5}$ The new recently proposed acute complex care model (ACCM) represents, at the moment, the hospital counterpart of CCM and is similarly aimed to ensure efficacious and effective care of acutely ill complex and poly-pathological patients (AICPPs), admitted to hospital and requiring high technological resources through pre-defined intra-hospital tracks and a global, multidisciplinary, patient-centered approach. ${ }^{6}$ The next step in the creation of a new health organization is represented by the establishment of an Internal Medicine Network that appropriately interconnect CCM and ACCM.

To identify a network model, which ensures an appropriate and comprehensive management of AICPPs, a literature review was carried out from December 2015 to May 2016 on the basis of keywords like network model, poly-pathological patients, integrated care, and core competencies in internal medicine. A total of 105 articles were selected and 25 representative articles were chosen to outline a new model to improve the management of Internal Medicine patients through pre-defined tracks connecting hospital and field according to levels of care intensity. $2,4-27$

\section{The Internal Medicine context in Italy}

According to a recent study on medical discharge records (SDO), the IM today in Italy takes in charge mainly elderly patients affected by complex diseases in phase of exacerbation. The first 10 diagnosis-related group (DRGs) were represented by cardiac failure, pulmonary edema, pneumonia, septicemia, stroke, chronic obstructive pulmonary disease, red blood cells abnormalities, renal failure, transient ischemic attack and liver cirrhosis. The mean hospital stay was 9.28 days (from 7 to 12,67) and the average weight of the top 10 DRGs was between 0.7 and 1.62. The Italian hospital receives $55 \%$ of the admissions in emergency. The differences between emergency and election are less evident where there is a territorial network efficiently organized.

The admissions to Internal Medicine represent $27 \%$ of urgent admissions and come from Emergency in $83 \%$ of cases documenting that the management of complex acute patients is one of the IM prevailing activities, requiring the internist's soft skills.

Tables 1 and 2 show the economic impact of the Internal Medicine Units (IMU) in Italy and the distribution of hospital admissions from Emergency Department (SDO data 2013). ${ }^{28,29}$

Table 1. Internal Medicine diagnosis-related group value in Italy.

Internal Medicine DRG value: 3,426,279.881€

All DRG total value $23,371,449.746 €$

Internal Medicine produces $14.6 \%$ of DRGs

Value is distributed by $50 \%$ between urgent and planned admissions Average DRG: $3682.19 €$

$3682.19 €$ emergency admissions average DRG

$4083.42 €$ planned admissions average DRG

Daily average value: $436.93 €$

DRG, diagnosis-related group. Source: SDO data, 2013. ${ }^{29}$

Table 2. Medical and surgical admissions burden in Emergency.

\begin{tabular}{|c|c|c|c|c|c|}
\hline Emergency admissions & $\%$ On total & Cases & $\%$ On total & Value $(€)$ & $\begin{array}{l}\text { Average DRG value } \\
\text { in Emergency }\end{array}$ \\
\hline Internal Medicine & $27 \%$ & - & - & - & - \\
\hline Neurology & $8 \%$ & - & - & - & - \\
\hline Cardiology & $4 \%$ & - & - & - & - \\
\hline Geriatrics & $3 \%$ & - & - & - & - \\
\hline Medical Area value & & $2,559,681$ & $77 \%$ & $7,002,007,375$ & 2735.50 \\
\hline Total Emergency admissions in Medical Area & $42 \%$ & - & - & - & - \\
\hline General Surgery & $10 \%$ & - & - & - & - \\
\hline Orthopedics and Traumatology & $8 \%$ & - & - & - & - \\
\hline Gynecology and Obstetrics & $6 \%$ & - & - & - & - \\
\hline Total Emergency admissions in Surgical Area & $24 \%$ & - & - & - & - \\
\hline Surgical Area value & & 744,019 & $23 \%$ & $5,167,383,079$ & 6945.23 \\
\hline Total & & $3,303,700$ & $100 \%$ & $12,169,390,454$ & 3683.53 \\
\hline
\end{tabular}

DRG, diagnosis-related group. Source: SDO data, $2013 .^{29}$ 


\section{Internal Medicine Unit mission}

\section{Internal Medicine Unit mission and specific features}

The IMU is the natural destination of acute patients with systemic or multi-organ diseases. The focal point is the diagnostic phase, conducted in hospital if possible alternative routes are not possible because of particular complexity, high technology need and/or monitoring or patient's frailty. ${ }^{10,11}$

The following features differentiate the hospital Internal Medicine specialist by Specialists operating in other care settings. ${ }^{12}$

- Emergency Department: mainly syndromic diagnosis, filter function, vital parameters stabilization.

- Specialist Divisions mono-organ or mono-apparatus: diagnosis already oriented.

- Field Residential Facilities: patients diagnosed and stabilized.

- General Practitioner (GP): preventive role and first diagnostic orientation, does not follow acute patients.

- Geriatrician: patients mostly fragile and complex from the social point of view; mainly oriented towards the rehabilitation of the post-acute chronic patient with persistent functional limitations.

In this new context, the Internal Medicine today:

- Manages the diagnosis and therapy of acute, complex, poly-pathologic, frail patients (Table 3) $)^{16,17}$ to select the acute poly-pathologic patient's priorities. $^{13,14}$

- Provides, with basic technologies, an effective response to the patients' needs arising from a wide variety of clinical problems, a proper use of spe- cialized high-tech equipment and the ability to respond to patient's needs with the most appropriate organizational form (hospitalization, outpatient department, day hospital), at different phases of the patient's medical history.

- Supports the correct management of the surgical patients (co-management) $)^{15}$ before and after surgery, in both inpatients and outpatients. This activity allows the reduction of costs and of the length of stay, avoiding complications linked to patients' comorbidities.

- The essential tool of the doctor-patient relationship is the clinical method. . $^{30,31}$

\section{Internal medicine network model}

The network model is a complex system arising from quantum physics. The model includes nodes and functions organized in adaptive hierarchies and multiple interconnections and dynamic to answer the changing needs, in qualitatively and quantitatively different ways. Each node change can alter all the system components (Figure 1). This organization needs to anticipate all the answers predicting the majority of patient's diagnosis and treatment needs. The GP, in this model, exerts preventive activities, guidance and follow-up of stabilized complex poly-pathological patients. Moreover, the spoke facilities are able to give appropriate answers to the acute patients, while in the field facilities rehabilitation or long-term care will become prevalent. The Hub structures are able to manage acute patients and, in addition, offer advanced technological assistance. The problem of patient's referral from one point to another of the network is given by the lack of standardized guidelines. The information transmission takes place

Table 3. Characteristics of the Internal Medicine patients. ${ }^{16,17}$

Adults, generally more than 75 years old

with more than 3 co-morbidities

with chronic diseases in acute phase

sometimes instable or critical

frail (more than $80 \%$ of patients need to be helped at home)

in many cases complex

sometimes disable or at risk to lose their abilities

in treatment with many drugs (more than 6 drugs a day)

with repeated hospital admissions

sometimes at risk of difficult discharge

needing integrated approach with different specialists

needing continuity of care

needing social support ( $3 \%$ are alone) 
still largely with paper. For the network optimization, the real-time information transmission through adequate information technology (IT) support would be fundamental. The extensive IT use would allow time saving and patient transport costs reduction.

The target of the IMN is the complex poly pathological patient that the network will follow during the natural history of his diseases. The main network problems are the contacts that allow the referral from one point to another. According to the degree of informatics system development, the contact points can be by computerized access or using telephone lines or faxes. Central role in the patient's referral is played by the case manager. The consequent steps to be followed in the network are: i) stratifying the patients according to gravity scores to establish the level of intensity of care needed; ii) admission to hospital; iii) clinical conditions stabilization using technological support and monitoring the patient; iv) referral to lower level of care intensity; v) regular patient's conditions checkup in the field to avoid the readmissions; vi) followup of the patient in the field facilities and by GP in order to empower the patient and to keep chronic, frail, poly-pathological people at home or out of the hospital, providing a social and health care continuum.

\section{Clinical data sharing}

As already presented at the 2014 European and Swiss Congress of Internal Medicine (ESCIM) ${ }^{18}$ the Internal Medicine network needs to share data of polypathological patients between hospital and field such as GPs, outpatient specialists, community health posts [presidi ospedalieri di prossimità (PTP); presidi os-

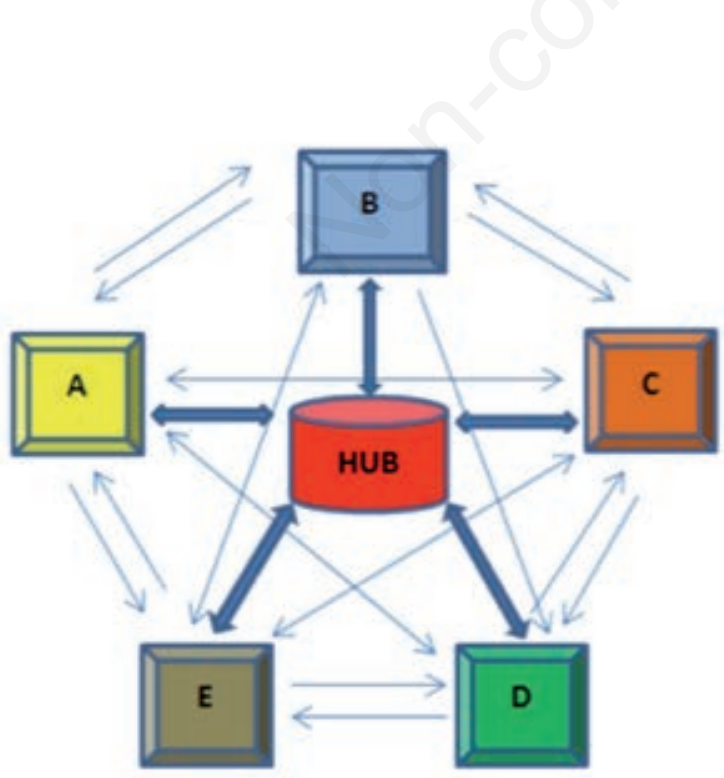

Figure 1. Internal Medicine Network. HUB, Hospital Internal Medicine; A, Low intensity Care Unit; B, Rehabilitation Unit; C, ADI (at Home Assistance); D, Field Facilities (minimum care level); E, General Practitioners. pedalieri territoriali (POT)] using computerized systems that enable communication among medical records programs already in use so that the clinical information flow follows the patient throughout his diagnostic-therapeutic path (PDTA).

The expected results of a new model of digital integration system inside the IMN are: i) reduction and rationalization of expenditure in the medical area; ii) increasing effectiveness, quality and safety with the centrality of the patient; iii) achieving stratification of patients in internal medicine who need hospitalization based on characteristics of gravity, acute illness, estimated duration of hospitalization; iv) avoiding continuous access to emergency care for chronic diseases to reduce inappropriate hospital admissions through the connection between primary care groups (PCGs) and hospital; v) defining different PDTA for patients hospitalized due to NCD; vi) implementing a new common model of medical records (electronic health records) (Table 4).

The electronic health record is a useful tool for the integrated patient's management. It is structured into a medical and a nursing part, both disease- and problem-oriented. It is built to lead to an actual global taking in charge, it allows a multidisciplinary approach; it promotes and enhances the level of communication and information sharing inside the working group; it reduces and makes essential the time to visit the patients and briefings. ${ }^{19,32,33}$

\section{Internal medicine network SWOT analysis}

The use of SWOT (Strengths, Weaknesses, Opportunities, Threats) analysis ${ }^{20}$ to define the Internal Medicine Network represents an innovative way to analyze the changed context. The SWOT analysis has been used as an instrument of internal mapping to define the role of the Internal Medicine Network in the integration hospital-field and to suggest the next steps to be taken to better define the network in a changing environment in which the tasks involved may not be completely understood. Our proposal suggests that a

Table 4. Electronic health records main items.

Social history (mobility, caregivers, etc.)

Drugs history (why this therapy?)

Use of severity index to allow a correct patient's allocation

Selecting the main diagnosis and generation of problems' check list Clinical and nursing diary management problem oriented, using specific diseases scores

Vital signs and exams trends

Discharge letter generation (including all the electronic health records' data) 
way to overcome the weaknesses and minimize the risk is to improve professional quality with training courses, and activation of diagnostic and therapeutic pathways to integrate hospital and GPs' care and longterm care, and patients' stratification according to the severity of their condition and type of disease. Among the Network strengths there is the ability to dynamize the patients' management stratifying them according to criteria shared among the different network actors. IMN SWOT analysis is showed in Table 5.

\section{Patients' stratification according to intensity of care}

The new model based on intensity of care has the ambitious goal of achieving the best clinical efficacy and assistance ensuring a sustainable economic engagement. ${ }^{21}$

The organization is divided into different levels of care, to manage each patient after an integrated medical and nursing assessment that takes into account the clinical condition and the complexity of care.

The applicability of a model according to intensity of care: i) requires flexibility taking into account the structure in which it is realized; ii) generates different organizational structures; iii) each level needs adequate presence of medical/nursing staff and technologies; iv) different pathways have to be provided depending on the characteristics of the patients; $v$ ) in the definition of responsibilities a central role is given to the hospital internist. ${ }^{6,34}$

Patients are assigned to the most appropriate setting (level) according to the assessment showed in Table 6.

Table 5. Strengths, weaknesses, opportunities, threats analysis: Internal Medicine Network.

\begin{tabular}{|c|c|c|c|}
\hline \multicolumn{4}{|c|}{ Internal Medicine Network SWOT analysis } \\
\hline Strengths & Weaknesses & Opportunities & Threats \\
\hline $\begin{array}{l}\text { To create a link among intensity } \\
\text { of care levels }\end{array}$ & $\begin{array}{l}\text { Low efficacy in defining intensity } \\
\text { of care level according to the } \\
\text { patients' needs }\end{array}$ & $\begin{array}{l}\text { To improve the ability in } \\
\text { stratifying the patients }\end{array}$ & $\begin{array}{l}\text { Risk of inappropriate referral of } \\
\text { patients who have not been } \\
\text { stabilized yet to lower intensity care } \\
\text { settings }\end{array}$ \\
\hline Dynamic patients' management & $\begin{array}{l}\text { Lack of adequate patients' } \\
\text { conditions stabilization }\end{array}$ & Length of stay reduction & $\begin{array}{l}\text { Re-admissions (revolving doors } \\
\text { phenomenon) }\end{array}$ \\
\hline To create sharing path of care & $\begin{array}{l}\text { Low Regional Authorities } \\
\text { control of proposed paths }\end{array}$ & $\begin{array}{l}\text { Setting up of integrated paths } \\
\text { and teams }\end{array}$ & Increased bureaucracy \\
\hline $\begin{array}{l}\text { To give key roles to the different } \\
\text { network actors }\end{array}$ & Low different roles awareness & $\begin{array}{l}\text { Improving the result-oriented } \\
\text { personnel's competencies }\end{array}$ & $\begin{array}{l}\text { System inadequate to answer the } \\
\text { patients' needs }\end{array}$ \\
\hline
\end{tabular}

Table 6. Intensity of care levels.

\begin{tabular}{|c|c|c|c|c|c|c|}
\hline $\begin{array}{l}\text { Level of } \\
\text { care }\end{array}$ & $\begin{array}{l}\text { Need of medical } \\
\text { presence }\end{array}$ & $\begin{array}{l}\text { Need of } \\
\text { continuous } \\
\text { monitoring }\end{array}$ & $\begin{array}{c}\text { Hemodynamics } \\
\text { stability }\end{array}$ & $\begin{array}{c}\text { Vital signs } \\
\text { monitoring } \\
\text { Instrumental } \\
\text { assistance }\end{array}$ & $\begin{array}{c}\text { Risk of } \\
\text { complication }\end{array}$ & $\begin{array}{l}\text { Type of } \\
\text { facility }\end{array}$ \\
\hline Minimum & No & No & Yes & No & No & $\begin{array}{c}\text { Community } \\
\text { Health Posts } \\
\text { (residential } \\
\text { facilities) }\end{array}$ \\
\hline Low & $\begin{array}{c}\text { Yes } \\
\text { Discontinuous }\end{array}$ & No & Yes & No & No & $\begin{array}{c}\text { Post-acute, } \\
\text { week-hospital } \\
\text { etc. }\end{array}$ \\
\hline Medium & Yes & No & Yes & Discontinuous & $\begin{array}{l}\text { Predictable } \\
\text { Controllable }\end{array}$ & $\begin{array}{c}\text { Hospital } \\
\text { Ordinary } \\
\text { Admission } \\
\text { Area }\end{array}$ \\
\hline High & Yes & Yes & No & Continuous & Yes & $\begin{array}{l}\text { Hospitalization } \\
\text { in High } \\
\text { Dependency } \\
\text { Unit }\end{array}$ \\
\hline Intensive & Yes & Yes & No & $\begin{array}{c}\text { Continuous } \\
\text { Dependency on } \\
\text { technological tools }\end{array}$ & Yes & $\begin{array}{c}\text { Intensive Care } \\
\text { Unit }\end{array}$ \\
\hline
\end{tabular}


Whereas about $25 \%$ of IM hospitalized patients need a more intensive care settings and treatments, an accurate clinical observation together with the use of score as Modified and National Early Warning Score for clinical instability, Index of Caring Complexity, Dependency Assistance Index or Ray score for care complexity are very important in patients' monitoring to promptly identify the adequate level of care needed by the patient. Actually, deaths and admissions to the intensive care unit might have been avoided if the patients' clinical deterioration had been noticed earlier. ${ }^{22}$

These patients have a mortality rate from 3 to 10 times greater of the entire series of hospitalized in Internal Medicine. ${ }^{35}$

\section{The internal medicine network in the hub and spoke model}

As stated by the literature, ${ }^{36}$ an organization according to intensity of treatment has to respect the following key points: i) an accurate identification of the medical care on which to base the model; ii) a well-defined strategy for differentiated allocation of staff to structural and technological areas depending on the level of medical care provided in the area; iii) an accurate definition of the types and features of patients targeted by each level of medical care; iv) an early exchange (starting from the patient's arrival in the Emergency Department) of information and medical knowledge among Emergency Department physicians and the physicians in charge of the initial stages of hospitalization; v) a precise definition of responsibilities in the different areas, operative and collaborative stages among physicians and medical staff, linking appropriately the different disciplines involved in the process.

Defining a model needs also an appropriate description of the stage subsequent to hospitalization to ensure a patient's path continuum from hospital and territory and vice versa. The application of PDTA for the main chronic diseases, shared and implemented by different specialists, is the most appropriate method to achieve a functional integration. In countries with growing number of elderly, PDTA allows to: i) improve the appropriateness of care; ii) define the correct territorial setting; iii) verify the costs, contributing to the sustainability of the health system. ${ }^{3}$

The following step, subsequent to the definition of the intensity of care model in treating hospitalized patients and PDTA to appropriately follow them in the territory, is the IMN organization according to the Hub and Spoke system already used for the specialist networks. The IMU Hub are located in hospitals identified as Hub for the catchment area, and are provided with the principal services, advanced tech- nological supports, specialties needed to deal with any diagnostic and therapeutic possibility both medically and surgically.

The IMU in peripheral hospitals and private accredited facilities can be considered as a spoke.

The network is completed by the stable patient care in the field facilities able to offer a minimum intensity of care level. ${ }^{23}$

Outpatient: GPs; $\mathrm{PCGs}^{24}$ and Outpatient Department with different specialties; integrated home care; health posts (PTP, POT); Alzheimer Evaluative Unit centers.

Residential: long-term care field facilities; assisted health residences (RSA); hospices, Rehabilitation Institutes.

\section{Hub Internal Medicine Center features}

- It receives patients from the Emergency/Urgency and Spoke centers.

- It has to be placed in a hospital with departmental organization and/or where there are multidisciplinary skills and technologies that enable management of many patients with high care needs.

- It has a structure with monitored beds and high technological equipment.

- It is equipped with a network digital system.

\section{Spoke Internal Medicine Center features}

- Mission is to treat patients with less severe clinical condition and medium-high clinical complexity.

- It is equipped to perform multi-parameter monitoring.

- It is provided by radiological and laboratory diagnostic facilities.

- Internal Medicine doctor on duty $24 \mathrm{~h}$ a day.

- It receives patients from the Emergency/Urgency and is connected with local services on the field.

\section{Territorial Low-Intensity Spoke Center and features}

- It receives patients from hospital general wards and from home.

- It is equipped with emergency medical service and periodic check-up of admitted patients.

\section{Low-intensity service without hospitalization}

- It receives patients from home.

- It performs secondary prevention activities.

\section{Differences between territorial and hospital assistance}

- Territory: i) proximity; ii) global taking charge; iii) continuous.

- Hospital: i) specialized assistance; ii) specific taking charge; iii) episodic. 


\section{Public-private partnership in a network model}

Partnerships enable the public sector to benefit from commercial dynamism, innovation and efficiencies, harnessed through the introduction of private sector investors who contribute their own capital, skills, and experience. ${ }^{25}$

Given respective strengths and weaknesses, neither the public sector nor private sector alone is in the best interest of the health system. The benefits of public-private partnerships in improving quality of services are the following: ${ }^{37} \mathrm{i}$ improved access and reach; ii) improved equity (reduced out of pocket expenses); iii) better efficiency; iv) opportunity to regulate and accountability; v) improved quality/rational practice; vi) imbibed best practices; vii) augmented resources, funds, technology, human resources.

The public-private partnership within a network model helps containing costs by offering services especially in disciplines that in recent years have been subjected to reducing beds number to meet the costcutting plans, ensuring quality standards required for accreditation. It can be realized both in speeding up hospital admissions and in reducing hospital length of stay. The care of the acute patients reduces the overcrowding of Emergency Room accelerating patients' admission and allowing appropriate management of them. The accredited private structures are, in fact, able to ensure a treatment according to intensity of care with sub-intensive areas that allow the monitoring of critical patients, at risk of instability. On the other hand, the public-private partnership provides cost-effective solutions in the management of stabilized patients, who need further assistance in low intensity areas of care (i.e., residential facilities like RSA, subacute units, rehabilitation units), contributing to the reduction in the length of hospital stay.

Such partnerships should be launched more and rigorously evaluated, and their lessons should be widely shared to guide policy makers in the effective use of this model.

\section{Patient discharge from the internal medicine unit}

The patient discharge is a very crucial point in the IMN, because it is very important to correctly draft summary discharge, to give patient and family members exhaustive information, to ensure early connection with GPs, to prescribe an appropriate therapy trying to optimize the patient compliance. In case of need of short distance control, it would be guaranteed preferential channels for outpatients' department access.
Nursing written discharge will ensure the health care plan continuity.

\section{Continuity of care and protected discharge}

The organization of this stage of the care process requires health and social patient needs preliminary identification, verifying guarantees and requirements for its fulfilment. It would especially emphasize the most appropriate answer to social care issues that are usually linked to health needs and to new and added disability (also in relation to a possible acute episode of illness), and related logistical situations (person living alone, vulnerability condition, lack of family support). If the prevailing need is the continuity of care it should be set up clinical pathways integrating hospital with GPs and home care nursing service. The choice of an appropriate pathway in the post-acute phase and an effective coordination of health activities and social care following discharge allows the reduction of inappropriate extensions of hospital stay and repeated hospitalizations and establishes a hospital-territory integration system ensuring the patient's continuity of care.

\section{Referrals}

The referral of patient needing to extend the hospital stay in a different care setting requires appropriate organization to ensure continuity of care. The patient transport should ensure the same level of care than the ordinary hospital stay. Moreover, it would be appropriate to refer to the Eherenwerth's classes of risk reported in Figure 2. ${ }^{26,38}$

\section{Critical issues}

- Poor number of ambulances available compared to the number of patients to be transferred.

- Waiting times.

- Need to ensure medical care for unstable patients (low availability of medical staff).

\section{Discussion}

The Internal Medicine Network proposes to allocate an appropriate care setting for Internal Medicine patient at different stages of the illness episode in the disease process. The proposed network system comprises: i) a phase of acute patients stabilization and stratification occurring in the Emergency Department and ending with the initial definition of in-hospital patient path; ii) the process of hospital response involving Internal Medicine that manages the internal medicine patients, identifying priorities, realizing the monitoring and defining the final diagnosis; iii) the 


\section{CLASS I and II}

The patient:

- Does not require or rarely requires monitoring of vital signs

- Does not need a venous line

- Does not require continuous administration of $\mathrm{O}_{2}$

- Not to be transferred to Intensive Care

During transport nurse attendance is requested.

\section{CLASS III}

The patient:

- Requires frequent monitoring of vital signs

- Needs a venous line

- Does not need invasive monitoring

- Can have mild impairment of consciousness with Glasgow coma scale (GCS) >9

- Can have mild to moderate respiratory distress

- Requires continuous $\mathrm{O}_{2}$ administration

During transport doctor and nurse presence is requested.

\section{CLASS IV}

The patient:

- Requires endotracheal intubation

- Requires ventilator support

- Needs two venous lines or central venous catheter

- There may be a state of consciousness impairment with GSC $<9$

- May require life-saving drugs

- Is transferred to Intensive Care Unit or other intensive care settings

During transport anesthesiologist and nurse presence is requested.

\section{CLASS V}

The patient:

- Cannot be completely stabilized

- Requires monitoring and invasive life support

- Requires lifesaving treatment during transport

During transport anesthesiologist and nurse presence is requested.

Figure 2. Critically ill patients transport (Eherenwerth's classes of risk). Data source: ASP Ragusa Procedura di trasporto secondario. Versione $n^{\circ} 00$ del 15.12.2011/RM, 2011. ${ }^{38}$ 
network system integrated with the field is able to define the next steps in the patients' path and to choose different care settings after the acute phase according to the patients' needs. The activity of Internal Medicine is documented by the hospital information system, connected to medical records archives and the information systems in use at district and general practitioners level. The integration of these systems allows the representation of the entire care pathway.

It is evident that the IM network proposed here is a model that can properly follow the poly-pathological complex patient at all stages of his illness and it is much more efficient as it is linked to territorial structures to relieve quickly Hub centers and hospitals congestion.

The positive experience of public-private partnership demonstrates how the synergy between public and private sectors can profitably be used not only in Internal Medicine, but also in other specialized fields in order to optimize the emergency network paths and help to reduce overcrowding of the emergency room.

The overall patient-centered problems assessment, integration, cooperation and coordination, effective communication are some simple rules to achieve tangible results in a complex system..$^{27,39}$

Compatible software use could effectively contribute to the patient's information transfer and to improve appropriateness and time optimization.

\section{Learning points}

- The Internal Medicine Network aims to give an appropriate answer to the patients' health needs.

- The target population consists in acutely ill complex and poly-pathological patients.

- IMN is organized according to intensity of care levels.

- The public-private partnership could be able to increase appropriateness reducing health costs.

- Patient's referral is a crucial point of the network, being a part of the care pathway.

\section{Conclusions}

Internal Medicine increasing central role in the management of AICPP needs a network model where to inscribe the different pathways according to the level of care intensity. The Internal Medicine Network represents the first practical application of this patientcentered global approach.

\section{References}

1. World Health Organization. Noncommunicable diseases - Health systems response to NCDs. Available from: http://www.euro.who.int/en/health-topics/Health-sys- tems/health-systems-response-to-ncds Accessed: 24 April, 2016.

2. World Health Organization. Better non-communicable disease outcomes: challenges and opportunities for health systems. Assessment Guide. Geneva: WHO Regional Office for Europe; 2014.

3. Tozzi VD, Longo F, Pacileo G, et al. PDTA standard per le patologie croniche. 11 ASL a confronto per la gestione della rete dei servizi per BPCO, tumore polmonare, ictus, scompenso cardiaco e artrite reumatoide. Biblioteca dell'economia d'azienda. Cergas-Bocconi Fiaso. Milano: Edizioni Egea; 2014. Available from: https:/www.unibocconi.it/wps/wcm/connect/72064c0b017f-4682-b36d-d651681d246f/PDTA.pdf?MOD= AJPERES

4. World Health Organization. Strengthening people-centred health services delivery in the WHO European Region: concept note. Geneva: WHO Regional Office for Europe; 2014.

5. Coleman K, Austin BT, Brach C, Wagner EH. Evidence on the Chronic Care Model in the new millennium thus far, the evidence on the Chronic Care Model is encouraging, but we need better tools to help practices improve their systems. Health Aff 2009;28:75-85.

6. Pietrantonio F, Orlandini F, Moriconi L, La Regina M. Acute Complex Care Model: An organizational approach for the medical care of hospitalized acute complex patients. Eur J Intern Med 2015;26:759-65.

7. Barry MJ, Edgman-Levitan S. Shared decision making - the pinnacle of patient-centered care. N Engl J Med 2012;366;9.

8. Stacey D, Bennett CL, Barry MJ, et al. Decision aids for people facing health treatment or screening decisions. Cochrane Database Syst Rev 2011;10:CD001431.

9. Peabody FW. The care of the patient. JAMA 2015; 313:1868.

10. Regione Emilia-Romagna. Delibera Giunta Regionale n. 419 del 10 aprile 2012. Requisiti specifici per l'accreditamento delle strutture di medicina interna. Agenzia Sanitaria e Sociale Regionale Emilia Romagna (Ottobre 2011, revisione 1): 1-34. Available from: http://assr.regione.emilia-romagna.it/it/servizi/normativa/autorizzazione-e-accreditamento/normativa-regionale/requisitispecifici-accreditamento/req-s-medicina-interna

11. Cournane S, Conway R, Byrne D, et al. Social deprivation and the rate of emergency medical admission for older persons. QJM 2016 [Epub ahead of print].

12. Scotti E, Pietrantonio F. The Hospital Internal Medicine Specialist today: a literature review and the SWOT analysis to elaborate a working proposal. Ital J Med 2013;7:278-86.

13. Orlandini F, Pietrantonio F, Moriconi L, et al. A model to improve the appropriateness in the management of acute poly-pathological patients: the acute complex care model. Ital J Med 2017;11:1-7.

14. Cranston M, Semple C, Duckitt R, et al. For the European Board of Internal Medicine Competencies Working Group. The practice of internal medicine in Europe: organisation, clinical conditions and procedures. Eur J Intern Med 2013;24:627-32.

15. Siegal E. Just because you can doesn't mean that you should: A call for the rational application of hospitalist comanagement. J Hosp Med 2008;3:398-402. 
16. Nardi R, Scanelli G, Borioni D, et al. The assessment of complexity in internal medicine patients. The FADOI Medicomplex Study. Eur J Intern Med 2007; 18:283-7.

17. Campanini M, Fontanella A, Nozzoli C, et al. La Medicina Interna Ospedaliera: tra complessità e intensità assistenziale verso una medicina sostenibile. Quad Ital J Med 2014;2:1-69.

18. Pietrantonio F, Patrizi C, Davoli Q, et al. INTEGRA: the simplicity of a new integration system to increase the effectiveness of the hospital-territory network. ESCIM Poster session 319, n 908. ESCIM European and Swiss Congress of Internal Medicine 2014, 14-16 May 2014, Geneva, Switzerland.

19. Cebul RD, Love TE, Jain AK, Hebert CJ. Electronic health records and quality of diabetes care. N Engl J Med 2011;365;9.

20. Armstrong M. A handbook of human resource management practice (10 $10^{\text {th }}$ edition). London: Kogan Page; 2006.

21. Chesi G, Nardi R. Severity Stratification of patients hospitalized on the Internal Medicine ward work: in progress Ital J Med 2013:7:231-3

22. Carberry M, Clements P, Headley E. Early warning systems 1: how helpful are early warning scores? Nursing Times 2014;110:12-4.

23. D'Amore F, Manfellotto D, Pastorelli R, et al. Proposta di organizzazione delle U.O. di Medicina Interna secondo il sistema "Hub e Spoke". Il Policlinico-Sezione pratica. 117. n 11. Nov 2010.

24. Stefani I, Scolari F, Croce D, Mazzone M. Integrated care in the management of chronic diseases an Italian perspective. Eur J Int Med 2016 [Epub ahead of print].

25. Sekhri N, Feachem R, Ni A. Public-private integrated partnerships demonstrate the potential to improve health care access, quality, and efficiency. Health Affairs 2011;30:1498-507.

26. Regione Piemonte BU42 20/10/2011. Deliberazione della Giunta Regionale 3 ottobre 2011, n. 19-2664. Attuazione Piano di rientro. Definizione dei percorsi clinico organizzativi del paziente. politraumatizzato. Available from: http://www.regione.piemonte.it/governo/bollettino/abbonati/2011/42/attach/dgr_02664_830 03102011.pdf Accessed: 7 September, 2016.

27. Nardi R, Masina M, Cioni G, et al. Generic - equivalent drugs use in internal and general medicine patients: distrust, confusion, lack of certainties or knowledge? Ital J Med 2014;8:80-109.

28. Pietrantonio F, Piasini L, Spandonaro F. Internal Medicine and emergency admissions: from a national Hospi- tal Discharge Records (SDO) study to a regional analysis. Ital J Med 2016;10:157-67.

29. Ministero della Salute. Rapporto annuale sull'attività di ricovero ospedaliero. Dati SDO 2013; luglio 2014. Roma: Dipartimento della Programmazione e dell'Ordinamento del Servizio Sanitario Nazionale Dir. Gen. della Programmazione sanitaria Ufficio VI; 2014.

30. Murri A. Quattro lezioni e una perizia. Il problema del metodo in medicina e biologia. Bologna: Zanichelli; 1972.

31. Cosmacini G. Storia della medicina e della sanità in Italia. Dalla peste nera ai giorni nostri. Roma: Editori Laterza; 2010.

32. Chesi G, Maccari S, Ligabue R, et al. Cartella Clinica Informatizzata per un Dipartimento di area internistica organizzato per intensità di cure: strumento per migliorare l'appropriatezza e la qualità delle cure sanitarie. (Electronic health record for an Internal Medicine department organized according to intensity-of-care levels: a tool to improve health care appropriateness and quality). Politiche Sanitarie 2012;13:109-24.

33. Cartella Clinica Elettronica Ospedaliera. Indicazioni per un progetto sostenibile. Associazione Italiana Sistemi Informativi in Sanità; 2012.

34. [The Editors]. Internal Medicine and hospital organization based on treatment intensity: the position of FADOI Emilia Romagna (Medicina Interna e organizzazione ospedaliera per intensità di cure: la posizione di FADOI Emilia Romagna). Ital J Med 2012;6:72-4.

35. Pietrantonio F, Orlandini F, Moriconi L, La Regina M. Implementing Acute Complex Care Model (ACCM): the checklist to evaluate acute patients at admission to stratify them according to pre-defined intra-hospital tracks. XIX Congresso Nazionale FADOI. Roma, 14-17 Maggio 2016 (Oral Communications).

36. Chesi G, Boni F. Ospedale e modelli organizzativi per intensità di cure: il punto di vista dell Internista. Ital J Med 2012;6:63-71.

37. Venkat Raman A, Bjorkman JW. Public private partnership in Health Care in India: Lessons for Developing Countries. London: Routledge; 2009.

38. ASP Ragusa Procedura di trasporto secondario. Versione $\mathrm{n}^{\circ} 00$ del 15.12.2011/RM. Available from: https://www. asp.rg.it/index.php?option=com_docman\&task=doc_det ails\&gid=1732\&Itemid=235 Accessed: 07 September 2016.

39. Pirmohamed M, James S, Meakin S, et al. Adverse drug reactions as cause of admission to hospital: prospective analysis of 18820 patients. BMJ 2004;3:15-9. 